\title{
NILAI-NILAI $\bar{U} L \bar{U} A L-' A Z M I$ \\ DALAM TAFSITR IBN KATHIR
}

\section{Fithria Khusno Amalia, Muhtar Solihin, Badruzzaman M. Yunus}

\author{
Fakultas Ushuluddin UIN Sunan Gunung Djati Bandung \\ Jl.A.H.Nasution 105 Cibiru Bandung 40614, Indonesia \\ E-Mail : fithriakhusnoamalia21@gmail.com
}

\begin{abstract}
Abstrak
Qașṣas al-Qur'ān merupakan bagian kandungan dari Alquran, yang salah satunya menjelaskan kisah Nabi-Nabi yang digelari $\bar{U} l \bar{u}$ al- 'Azmi, banyak ulama mengatakan bahwa Nabi-Nabi yang diberi gelar $\bar{U} l \bar{u}$ al- 'Azmi merupukan Nabi yang sangat sabar terhadap ujian yang Allah Swt., dibanding dengan Nabi-Nabi yang lain, namun apakah dalam Alquran hanya menjelaskan kesabaran saja? Perlu pula untuk mengetahui bagaimana nilai-nilai yang terkandung dalam kisah $\bar{U} \bar{u}$ al-'Azmi dalam Alquran, penulis menggunakan penaifsiran Ibn Kathir sebagai mufasir yang condong kepada al-Riwāyah sebagai sandaran dalam kisah-kisah Alquran. Penelitian ini bersifat kualitatif, yang berbentuk library research. Kesimpulan dari penelitian ini ialah nilai-nilai $\bar{U} l \bar{u}$ al-'Azmi dalam Alquran meliputi: (1). Bersyukur, (2). Dzi hijr (memiliki daya juang), (3). Terbuka, (4). Rendah hati, (5). Pembelajar, (6). Gigih, (7). Semangat, (8). Pantang menyerah, (9). Tawakal, (10). Ilahiyah (terkoneksi dengan Allah), (11). Pemenang, (12). Pengendalian diri, (13). Patuh, (14). Tunduk, (15). khusyu, (16). Keyakinan, (17). Lembut hati, (18). Sopan, (19). Keteguhan, (20). Keistiqamahan, (21). Teladan, (22). Tidak pengecut dan (23). Tangguh.
\end{abstract}

\section{Kata Kunci :}

$\bar{U}$ üal-'Azmi; Ibn Kathìr; nilai-nilai.

\begin{abstract}
Qașas al-Qur'ān is part of the content of the Qur'an, one of which explains the story of the Prophets who are dubbed $\bar{U} \bar{u}$ al-'Azmi, many scholars say that the Prophets who were given the title $\bar{U} l \bar{u}$ al-'Azmi is a very patient prophet of the test which Allah Almighty gives, compared to the other Prophets, but does the Quran only explain patience? It is also necessary to know how the values contained in the story of Ulu al-'Azmi in the Qur'an; the author uses Ibn Kathi's commentary as a mufassir leaning towards al-Riwāyah as a backstroke in the Quranic tales. This research is qualitative, in the form of library research. This study concludes that the values of $\bar{U} \bar{l} \bar{u}$ al-'Azmi in the Qur'an include: (1). Grateful, (2). Dzi hijr (have fighting power), (3). Open, (4). Humble, (5). Learners, (6). Persistent, (7). Spirit, (8). Abstinence, (9). Tawakal, (10). Divine (connected with God), (11). Winner, (12). Selfcontrol, (13). Obedient, (14). Submit, (15). Khusyu, (16). Confidence, (17). Softhearted, (18). Polite, (19). Persistence, (20). Consistent, (21). Example, (22). No cowards and (23). Tough
\end{abstract}

Keywords:

$\bar{U} \bar{u}$ al- 'Azmi; Ibn Kathìr; values.

\section{A. PENDAHULUAN}

Agama Islam, merupakan salah satu agama terbesar yang dianut oleh umat Islam di dunia, salah satu ajarannya ialah untuk menjamin kebahagiaan hidup pemeluknya di dunia dan di akhirat yang termaktub dalam
Alquran dan Hadith. ${ }^{1}$ Salah satu isi dari kandungan Alquran adalah kisah-kisah terdahulu (Qașaṣ al-Qur'an) yang memberitakan tentang hal ihwal umat yang telah lalu, nubuwwat (kenabian) yang

\footnotetext{
${ }^{1}$ Quraish Shihab, Membumikan Al-Quran: "Fungsi dan Peran Wahyu dalam Kehidupan Masyarakat”, (Bandung: Mizan Pustaka, 2013), 45.
} 
terdahulu dan peristiwa-peristiwa yang telah terjadi. Ia menceritakan semua keadaan mereka dengan cara menarik dan mempesona. ${ }^{2}$

Secara umum kisah-kisah Alquran terbagi ke dalam tiga bentuk; pertama, kisah para Nabi yang mengandung dakwah mereka pada kaumnya, dengan mukjizat-mukjizat untuk memperkuat dakwahnya, sikap orang-orang yang memusuhinya, tahapan-tahapan dakwah dan perkembangannya serta akibat-akibat yang diterima oleh mereka yang mempercayai ataupun yang mendustakannya. Seperti; kisah Nabi Nuh, Ibrahim, Musa, Harun, Isa, Muhammad dan Nabi-Nabi serta Rasul lainnya. Kedua, menceritakan peristiwaperistiwa yang terjadi pada masa lalu dan orang-orang yang tidak dipastikan kenabiannya. Seperti; dua putra Adam, kisah Talut dan Jalut, kisah ribuan orang yang keluar dari kampung halaman karena takut mati, penghuni gua, Zulkarnain, Karun, orangorang yang menangkap ikan pada hari Sabtu (Ashäb al-Sabt), Maryam, Ashāb al-Ukhdud, Ashāb al-Fîl dan lain-lain. Ketiga, kisah-kisah yang berhubungan dengan peristiwa-peristiwa yang terjadi pada masa Rasulullah, seperti perang Badar, perang Uhud, perang Hunain, perang Tabuk, perang Ahzab, hijrah Nabi dan sahabat, Isra mi'rajj, dan lain-lain.

Di antaranya kisah yang masuk dalam kelompok pertama adalah kisah $\bar{U} l \bar{u}$ al-'Azmi dalam Alquran, yaitu Nabi Nuh, Nabi Ibrahim, Nabi Musa, Nabi Isa dan Nabi Muhammad Saw.

Penyebutan nama-nama nabi $\bar{U} l \bar{u} a l$-'azmi ini terdapat di dalam dua buah ayat:

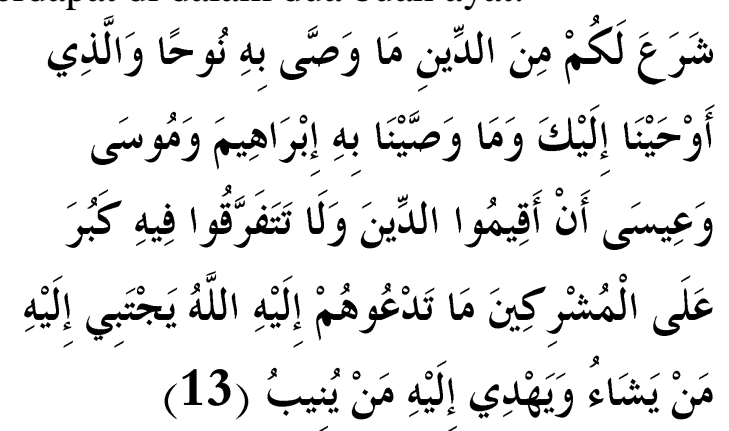

2 Manna' Khalil al- Qattan, Studi Ilmu-ilmu alQuran, judul asli: Mabāhith fì 'ulüm al-Qurān, penj. Mudzakir, cet. Ke-13, (Bogor: Pustaka Litera Antar Nusa, 2009), 436.
"Dia telah mensyariatkan kepadamu agama yang telah diwasiatkan-Nya terhadap Nuh dan apa yang telah diwahyukan Muhammad dan apa yang telah diwasiatkan kepada Ibrahim, Musa dan Isa yaitu tegakkanlah agama dan janganlah kamu berpecah belah di dalamnya. Sangat berat bagi orang-orang musyrik untuk mengikuti agama yang kamu serukan terhadap mereka. Allah memilih orang yang dikehendaki terhadap agama tauhid dan memberi petunjuk kepada bagi orang yang kembali (kepada-Nya)." (Al-Shūra[42]:13)

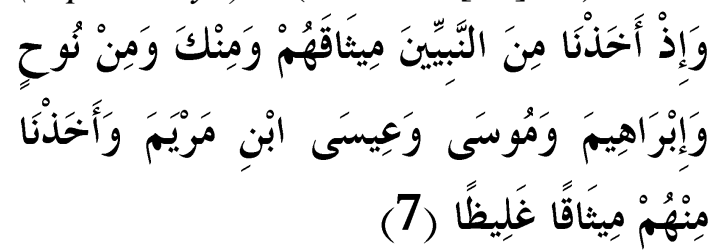

"Iingatlah ketika kami mengambil perjanjian dari para nabi dan dari engkau, dari Nuh, Ibrahim, Musa dan Isa putra Maryam, dan kami telah mengambil dari mereka perjanjian yang teguh. "( AlAhzāb[33]:7)

Selain itu, kata ulu $\bar{u}$ al-'Azmi itu sendiri terdapat di dalam surat al-Ahquāf: [46]:35:

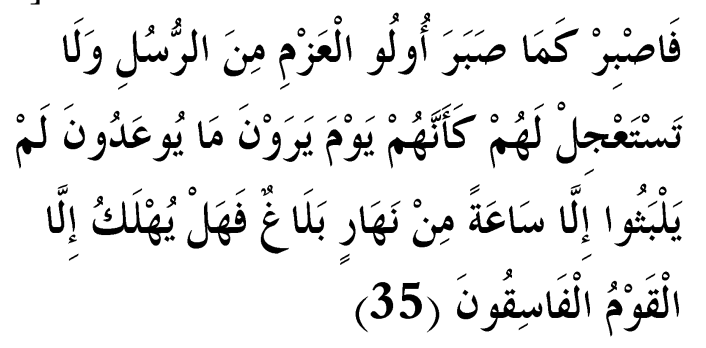

"Bersabarlah Muhammad sebagaimana kesabaran rasul-rasul yang memiliki keteguhan hati dan janganlah meminta agar azab disegerakan untuk mereka. Pada hari mereka melihat azab yang dijanjikan, mereka merasa seolah-olah mereka tinggal hanya sesaat saja pada siang hari. Tugasmu hanya menyampaikan. Maka tidak ada yang dibinasakan kecuali kaum yang fasik (tidak" (Al-Ahqāf[46]:35)

Ayat di atas menjelaskan bahwa Allah memerintahkan agar Nabi Muhammad bersabar sebagaimana kesabaran Rasul-Rasul 
yang memiliki keteguhan hati ( $u \bar{u}$ al-'Azmi). Tentunya dari hal tersebut penulis berpendapat bahwa kesabaran $\overline{U l} \bar{u}$ al-'Azmi itu memiliki nilai-nilai kesabaran dalam kehidupan mereka yang patut kita jadikan contoh. Karena Alquran sendiri sebagai kitab pedoman dari semua kitab ilahi, diturunkan untuk tujuan membentuk Insān al-Kämil, yaitu manusia yang benar-benar memiliki jiwa kemanusiaannya. Sesungguhnya misi dakwah para Nabi (terlepas dari tingkatannya) adalah sama, yakni untuk menjadikan manusia yang benar-benar manusia secara realitas. ${ }^{3}$

Kisah-kisah $\overline{U l} \bar{u} a l$ - 'Azmi ini tidak hanya sekali dipaparkan dalam Alquran. Tetapi disebutkan beberapa kali atau bisa disebut tiqrär (pengulangan) dalam bahasa Alquran.

Adapun hikmah pengulangan kisah itu sendiri, menurut Manna' Khalil al-Qattan antara lain: menjelaskan ke-balaghah-an Alquran dalam tingkat paling tinggi, menunjukkan kehebatan mukjizat Alquran, memberikan perhatian besar terhadap kisah tersebut agar pesan-pesannya lebih berkesan dan melekat dalam jiwa, dan setiap kisah memiliki maksud dan tujuan yang berbeda. ${ }^{4}$

Dari hikmah pengulangan kisah di atas, penulis berpendapat bahwa pengulangan kisah itu dimaksudkan agar nilai-nilai yang hendak disampaikan oleh Alquran agar mendapatkan perhatian lebih. Dalam hal ini kisah-kisah $\overline{U l} \bar{u}$ al-'Azmi lah yang menjadi sorotan. Penulis memilih tafsir Ibn katsìr sebagai media yang akan mengantarkan pada pengambilan nilainilai yang dimiliki oleh Nabi-Rasul dalam Alquran. karena melihat dari karakteristik tafsir tersebut yang bermetode tahlili dan bersumber ma'thür.

\section{B. PEMBAHASAN}

3 Abū Kauthar al-Habshi dan 'Ali Yahya , Membangun Generasi Qurani "Pandangan Imam Khomeini dan Syahid Muthahhari” cet. 1, (Jakarta: Citra, 2012), 6.

4 Manna' Khalil al- Qațan, Studi Ilmu-ilmu alQuran, 389.

\section{Pengertian Nilai}

Nilai yang dalam bahasa inggris disebut value merupakan istilah yang bisa ditemukan di salah satu cabang ilmu filsafat. Yakni aksiologi (filsafat ilmu). Aksiologi itu sendiri berasal dari kata axios, yakni dari Bahasa Yunani yang berarti nilai dan logos yang berarti teori. Dengan demikian, maka aksiologi menurut Amsal Bakhtiar adalah "teori tentang nilai". Sedangkan menurut Suriasumantri aksiologi diartikan sebagai teori nilai yang berkaitan dengan kegunaan dari pengetahuan yang diperoleh.

Adapun pengertian nilai itu sendiri menurut para ahli dunia banyak sekali, diantaranya:

a. Menurut bahasa yang terdapat dalam kamus besar bahasa Indonesia nilai adalah sesuatu yang berharga, angka yang mewakili prestasi, ukuran, bermutu, menunjukan kualitas, dan berguna bagi manusia. $^{5}$

b. Sedangkan Sidi Gazalba mengartikan nilai adalah sesuatu yang bersifat abstrak dan ideal. Nilai bukan kongkrit, bukan fakta, tidak hanya soal penghayatan yang dikehendaki atau tidak dikehendaki, yang disuakai atau yang tidak disukai. Nilai itu terletak antara hubungan subjek dan objek, seperti halnya garam mejadi berarti ketika ada orang yang membutuhkannya, emas menjadi berharga setelah ada orang yang mencarinya. ${ }^{6}$

c. Dalam pengertian lain, nilai adalah konsepsi-konsepsi abstrak dalam diri manusia atau masyarakat, mengenai halhal yang dianggap buruk dan salah. ${ }^{7}$

d. Menurut Chabib Thoha nilai merupakan sifat yang melekat pada sesuatu (sistem kepercayaan) yang berhubungan dengan

${ }^{5}$ Daryanto, Kamus Lengkap Bahasa Indonesia (Surabaya: Apollo, 1998), 412.

${ }^{6}$ Mawardi Lubis, Evaluasi Pendidikan Nilai: Perkembangan Moral Keagamaan Manasiswa PTAIN (Yogyakarta: Al-Ruzz Media, 2009), 20.

${ }^{7}$ Muhaimin \& Abdul Mujib, Pemikiran Pendidikan Islam (Bandung: Trigenda Karya, 1998), 110 . 
subjek yang memberi arti (manusia yang menyakininya). ${ }^{8}$

\section{Pengertian Ūlū Al-'Azmi}

Secara etimologi, kata $\bar{U} \bar{l} \bar{c}$ al-'Azmi terdiri dua suku kata "Ulu" dan "al- 'Azmi". Lafal $\bar{U} \bar{u}$ merupakan kata khusus yang menunjukkan makna jamak yang tidak ada asal kata mufradnya, sedang bila digunakan untuk mufrad menggunakan kata dzu yang berarti "memiliki", baik makhluk yang berakal maupun tidak.

Sedangkan kata "al- 'Azmi" merupakan mașdar, dalam Alquran kata "al- 'Azmi" mempunyai berbagai bentuk. Adapun dalam bentuk tașifi di dalam Alquran terulang lima kali, lalu bentuk kata kerja lampau tiga kali dan satu kali dalam bentuk masa kini dan mendatang, (fi îl mudari).

\section{Biografi Ibn Kathỉr}

Nama asli Ibn Kathìr ialah al-Hafizh Imaduddin Isma'il ibn Amr ibn Katsir ibn Dhau' ibn fira' al-Bashrawi. al-Quraisyi alDimasyqi. Adapaun Namu Kunsyahnya ialah Abū al-Fida'. Lahir tahun $700 \mathrm{H}$ dan meninggal tahun $744 \mathrm{H}^{10}$ Ayahnya merupkan orang Bashra, bernama Abu Hafsh Umar Ibn Kathï. Ia adalah salah seorang alim di kotanya, imam dan khatib di kampungnya. Ayahnya wafat ketika Ibn Kathīr berumur tiga tahun. Selanjutnya kakaknya bernama Abd al-Wahab yang mendidik dan mengasuh Ibn Kathir yang masih kecil Basrah. ${ }^{11}$ Ibn Kathīr menuju ke Damaskus untuk mencari ilmu, dengan belajar Fiqih, Hadith, Tafsir, Sejarah dan Bahasa,

\footnotetext{
${ }^{8}$ Zaim EL-Mubaroh, Membumingkan Pendidikan Nilai Mengumpulkan yang Terputus dan Menyatukan yang Tercerai,,7.

${ }^{9}$ Ibn Mandzür, Lisān al-'Arāb, cet.1, jilid 15 (Beirut: Dār al-Sadr, 1990), 438.

${ }^{10}$ Muḥammad Ali Al-Ṣabuni, Al-Ṭibyān fì Ulüm al-Qur'ān judul terjemah: Ikhtisar Ulumul Qur'an Praktis, penj. Muhammad Qodirun Nur, cet. 1 (Jakarta: Pustaka Amani, 2001), 313.

${ }^{11}$ Solah Abdul Fatah Al-Kholidi, Ta'rīf AlDarisīn Bimanāhij al- Mufasirīn, cet. V (Damaskus: Dār al-Qolam, 2012 M / 1433 H), 381.
}

hingga ia dapat menguasai banyak ilmu. ${ }^{12}$ Ibn Kathïr selesai menghafalkan Alquran genap di usia sebelas tahun. Kemudian belajar Tafsir dari pembesar ulama, salah satunya Ibn Taimiyah. $^{13}$

Ibn Kathïr adalah seorang ulama besar yang menguasai berbagai ilmu terutama Sejarah, Hadith dan Tafsir. Al-Zahabi mengatakan: "Ia adalah imam al mufti, ahl alHadith yang jeli, ahl fiqh yang berbakat, mufasir yang banyak menuqil, dan mempunyai karangan-karangan yang cukup berbobot".

Di akhir usianya Ibn Kathir diuji dengan kebutaan. Ibn al-Jazāri salah seorang murid dari Ibn Kathï memberitahu Ibn Kathï berpesan kepadanya: Aku masih tetap menulis kitab (Jami' al-Masānid) pada waktu malam dengan cahaya yang semakin meredup sehingga mengakibatkan pandanganku semakin melemah. ${ }^{14}$

\section{Sumber, Metode dan Corak Tafsir Ibn \\ Kathir}

Secara sederhana metodologi penafsiran adalah metode tertentu yang digunakan oleh mufasir dalam menafsirkan Alquran. Pada umumnya metode ini terbagi menjadi empat, yaitu metode ijmali, tahlili (analitis ), muqārin ( perbandingan ), maudhu' $i$ ( tematik ). ${ }^{15}$ Setiap metode yang digunakan pasti memiliki suatu ciri dan spesifikasi masing-masing.

Tafisr Al-Qur'ān al- Ažim ini dapat digolongkan sebagai salah satu tafsir dengan metode tahlili (analitis). Karena dalam menafsirkan setiap ayat, Ibn Kathïr menjelaskannya secara rinci dengan mencantumkan beberapa periwayatan yang lalu digunakan sebagai pendukung dari argumentasinya.

Adapun cara beliau menafsirkan adalah dengan menyebutkan ayat lalu

\footnotetext{
${ }^{12}$ Muhammad Az-Zuhaily, Ibn Kathir : Al-Hafidz al-Mufassir, 74.

${ }^{13}$ Solah Abdul Fatah Al-Kholidi, Ta'rīf AlDarisin Bimanāhij al- Mufasirīn, 387.

${ }^{14}$ Solah Abdul Fatah Al-Kholidi, Ta'rīf AlDarisin Bimanāhij al- Mufasirin ,386.

${ }^{15}$ Mawardi Abdullah, Ulumul Qur'an (Yogyakarta: PustakaPelajar, 2011), 167.
} 
menafsirkannya dengan istilah yang mudah dan sederhana. Di samping beliau mengambil ayat-ayat lain sebagai shahid, juga sekaligus membandingkannya dengan ayat-ayat tersebut, sehingga makna dan muradnya menjadi jelas. Cara yang demikian ini sangat menolong dalam tafsir ma'thūr, sehingga para mufasir menyebutnya sebagai Tafsir al-Qur'an bi alQur'an. ${ }^{16}$

Yang dimaksud dengan metode tahlili adalah menafsirkan ayat-ayat Alquran dengan memaparkan ayat-ayat Alquran dan memaparkan berbagai aspek yang terkandung di dalam ayat-ayat yang sedang ditafsirkan itu serta menerangkan makna-makna yang tercakup didalamnya sesuai dengan keahlian dan kecenderungan dari mufasir yang menafsirkan ayat-ayat tersebut.$^{17}$

Dalam tafsirnya terhadap kalamullah, biasanya Ibn Kathïr menggunakan Hadith dan riwayat, menggunakan ilmu Jarh wa alTa'dil, melakukan komparasi berbagai pendapat dan mentarjih sebagiannya, serta mempertegas kualitas riwayat-riwayat Hadith yang sahih dan yang $d h a i f^{18}$

Tafsir Ibn Kathï adalah salah satu kitab tafsir yang terkenal dengan menggunakan mendekatan periwayatan atau yang biasa disebut tafsir bi al ma'thür. Dalam kitab tafsirnya, Ibn Kathir lebih banyak mencantumkan periwayatan baik dari HadithHadith Nabi, perkataan para sahabat dan tabi'in sebagai sumber dari argumentasinya, Tak jarang Ibn Kathïr juga memberikan penjelasan tentang jarh dan ta'dil pada periwayatan, mensahihkan dan mendhaifkan Hadith. $^{19}$

${ }^{16}$ Muhammad Ali Al-Ṣabuni, Al-Tibyan fi Ulūm al-Qur'ān, judul terjemah : Ikhtisar Ulumul Qur'an Praktis, penj. Muhammad Qodirun Nur, Cet. 1 (Jakarta: Pustaka Amani, 2001), 313.

${ }^{17}$ Mawardi Abdullah, Ulumul Qur'an (Yogyakarta: Pustaka Pelajar, 2011), 168.

18 Manna' Khalil al-Qattan, Mabahith fí 'Ulum al-Qur'ān, terj. Aunur Rafiqel_Mazni, (Jakarta: Pustaka al-Kautsar, 2005), 456.

${ }^{19}$ Muhammad Husain al Dzahabī, Al-Tafsīir wa al mufassirūn (Qahirah: Dār al- Hadith, 2005M), 211.
Corak penafsiran dalam kitab Ibn Kathīr adalah menitikberatkan masalah fiqih. Beliau mengetengahkan perbedaan pendapat di kalangan ulama fiqih dan menyelami mazhaab-mazhab serta dalil-dalil yang dijadikan pegangan oleh mereka, manakala membahas tentang ayat yang berkaitan dengan masalah hukum. Tetapi meski demikian, beliau mengambil cara yang pertengahan, singkat, dan tidak berlarut-larut sebagaimana yang dilakukan oleh kebanyakan ulama fiqih ahli tafsir dalam tulisan-tulisan mereka. ${ }^{20}$

\section{Nilai-Nilai Dalam Kisah Ūlū 'Azmi}

Nilai-nilai dalam kisah $\bar{U} \bar{u}$ al-'Azmi dapat dilihat dalam tabel di bawah ini.

Tabel. I

\begin{tabular}{|c|c|c|c|}
\hline $\begin{array}{l}\mathbf{N} \\
\mathbf{O}\end{array}$ & $\begin{array}{c}\text { AYAT } \\
\text { ALQURAN }\end{array}$ & $\begin{array}{c}\text { KONTEKS } \\
\text { AYAT }\end{array}$ & NILAI \\
\hline 1 & $\begin{array}{ll}\text { QS } & \text { al- } \\
\text { Isrā[17]:3 }\end{array}$ & \begin{tabular}{lr}
\multicolumn{2}{l}{ Bersyukur (atas } \\
segala nikmat \\
dalam bentuk \\
apapun)
\end{tabular} & Bersyukur \\
\hline 2 & $\begin{array}{l}\text { QS. Al-Najm } \\
(53): 52\end{array}$ & $\begin{array}{l}\text { Pantang } \\
\text { menyerah } \\
\text { menghadapi } \\
\text { kezaliman dan } \\
\text { kedurhakaan }\end{array}$ & $\begin{array}{l}\text { Dzi hijr } \\
\text { (memiliki } \\
\text { daya } \\
\text { juang) }\end{array}$ \\
\hline 3 & $\begin{array}{l}\text { QS.Al- } \\
\text { 'Arāf[7]:69 }\end{array}$ & $\begin{array}{l}\text { Mendengarkan } \\
\text { nasihat dari } \\
\text { siapapun, } \\
\text { bersyukur atas } \\
\text { segala nikmat } \\
\text { dan karunia } \\
\text { Allah }\end{array}$ & $\begin{array}{l}\text { Terbuka, } \\
\text { rendah hati }\end{array}$ \\
\hline 4 & $\begin{array}{l}\text { QS. } \\
\text { 'Arāf[7] } \\
: 69\end{array}$ & $\begin{array}{l}\text { Menjadikan } \\
\text { kisah terdahulu } \\
\text { sebagai } \\
\text { pelajaran }\end{array}$ & Pembelajar \\
\hline 5 & $\begin{array}{l}\text { QS. Al-Qamar } \\
{[54]: 9}\end{array}$ & $\begin{array}{l}\text { Menghadapi } \\
\text { pengingkaran } \\
\text { sebesar apapun }\end{array}$ & Gigih \\
\hline 6 & $\begin{array}{l}\text { QS. Hūd[11] } \\
: 25\end{array}$ & Semangat & Semangat \\
\hline 7 & $\begin{array}{l}\text { QS Hūd[11] } \\
: 27\end{array}$ & $\begin{array}{l}\text { Pantang } \\
\text { menyerah }\end{array}$ & $\begin{array}{l}\text { Pantang } \\
\text { menyerah }\end{array}$ \\
\hline 8 & $\begin{array}{l}\text { QS. Hūd[11] } \\
: 36\end{array}$ & Tawakal & Tawakal \\
\hline 9 & QS. Nuh[71]:5 & Allah sebagai & Ilahiyah \\
\hline
\end{tabular}

${ }^{20}$ Muhammad Husain al-Dzahabī, Al-Tafsīir wa al mufassirǖ, 214. 


\begin{tabular}{|c|c|c|c|}
\hline & & $\begin{array}{l}\text { tempat } \\
\text { bergantung }\end{array}$ & $\begin{array}{l}\text { (terkoneksi } \\
\text { dengan } \\
\text { Allah) }\end{array}$ \\
\hline 10 & $\begin{array}{l}\text { QS. } \\
\text { Hūd[11]:38 }\end{array}$ & $\begin{array}{l}\text { Mendapatkan } \\
\text { pertolongan } \\
\text { Allah }\end{array}$ & Pemenang \\
\hline 11 & $\begin{array}{l}\text { QS. } \\
\text { Hūd[11]:40 }\end{array}$ & $\begin{array}{l}\text { Keselamatan } \\
\text { akan } \\
\text { didapatkan, } \\
\text { Hasil diserahkan } \\
\text { pada Allah }\end{array}$ & $\begin{array}{l}\text { Ilahiyah } \\
\text { (terkoneksi } \\
\text { dengan } \\
\text { Allah) }\end{array}$ \\
\hline 12 & $\begin{array}{l}\text { QS. } \\
\text { Hūd[11]:42 }\end{array}$ & $\begin{array}{l}\text { Mendapatkan } \\
\text { perlindungan, } \\
\text { pertolongan dan } \\
\text { pemeliharaan- } \\
\text { Nya. }\end{array}$ & Pemenang \\
\hline 13 & $\begin{array}{l}\text { QS. } \\
\text { Ṭaha[20]:39 }\end{array}$ & $\begin{array}{l}\text { Yakin akan } \\
\text { rencana Allah }\end{array}$ & $\begin{array}{l}\text { Ilahiyah } \\
\text { (terkoneksi } \\
\text { dengan } \\
\text { Allah) }\end{array}$ \\
\hline 14 & $\begin{array}{ll}\text { QS. } & \text { Al- } \\
\text { Qașas:17 } & \end{array}$ & $\begin{array}{l}\text { Tidak menolong } \\
\text { orang yang } \\
\text { berdosa }\end{array}$ & $\begin{array}{l}\text { Pengendali } \\
\text { an diri }\end{array}$ \\
\hline 15 & $\begin{array}{l}\text { QS. Al- } \\
\text { 'Arāf[7]:144 }\end{array}$ & Bersyukur & Bersyukur \\
\hline 16 & $\begin{array}{lr}\text { QS. } & \text { Al- } \\
\text { Baqarah[2]:67 }\end{array}$ & $\begin{array}{ll}\text { Patuh dan } \\
\text { bertawakal }\end{array}$ & $\begin{array}{l}\text { Patuh, } \\
\text { tawakal }\end{array}$ \\
\hline 17 & $\begin{array}{l}\text { QS. Al- } \\
\text { Kahf[18]:67 }\end{array}$ & $\begin{array}{l}\text { Tidak sombong } \\
\text { dan tidak lelah } \\
\text { mencari ilmu }\end{array}$ & $\begin{array}{l}\text { Pembelajar } \\
\text { an }\end{array}$ \\
\hline 18 & $\begin{array}{l}\text { QS. } \\
\text { 'Ali'Imrān[3] } \\
: 49\end{array}$ & $\begin{array}{l}\text { Ketundukan dan } \\
\text { kekhusyuan }\end{array}$ & $\begin{array}{l}\text { Tunduk, } \\
\text { khusyu }\end{array}$ \\
\hline 19 & $\begin{array}{l}\text { QS. } \\
\text { 'Ali'Imrān[3]: } \\
52\end{array}$ & Berserah diri & Tawakal \\
\hline 20 & $\begin{array}{ll}\text { QS. } & \text { Al- } \\
\text { Baqarah } & \\
{[2]: 136} & \\
\end{array}$ & $\begin{array}{lr}\text { Percaya } & \text { baik } \\
\text { secara } & \text { rinci } \\
\text { maupun global }\end{array}$ & Keyakinan \\
\hline 21 & $\begin{array}{l}\text { QS. } \\
\text { Taubah } \\
\text { [9]:114 }\end{array}$ & $\begin{array}{l}\text { Lembut hati dan } \\
\text { sopan }\end{array}$ & $\begin{array}{l}\text { Lembut } \\
\text { hati, sopan }\end{array}$ \\
\hline 22 & $\begin{array}{l}\text { QS. Al- } \\
\text { Baqarah [2] : } \\
124\end{array}$ & $\begin{array}{l}\text { Melaksanakan } \\
\text { perintah } \\
\text { maupun } \\
\text { larangan } \\
\text { dengan sebaik- } \\
\text { baiknya }\end{array}$ & Patuh \\
\hline 23 & $\begin{array}{l}\text { QS. } \\
\text { Șāfāt[37]:102 }\end{array}$ & $\begin{array}{l}\text { Keteguhan dan } \\
\text { keistiqamahan }\end{array}$ & $\begin{array}{l}\text { Keteguhan, } \\
\text { keistiqama } \\
\text { han }\end{array}$ \\
\hline 24 & $\begin{array}{l}\text { QS. Al- } \\
\text { An‘ }{ }^{-} \quad \text { m[6]:79 }\end{array}$ & $\begin{array}{l}\text { Mengesakan } \\
\text { Allah }\end{array}$ & $\begin{array}{l}\text { Ilahiyah } \\
\text { (terkoneksi } \\
\text { dengan } \\
\text { Allah) }\end{array}$ \\
\hline 25 & QS. & Keteladanan & Teladan \\
\hline
\end{tabular}

\begin{tabular}{|c|c|c|c|}
\hline & $\begin{array}{l}\text { Mumtahanah[ } \\
60] \text { : } \\
4\end{array}$ & & \\
\hline 26 & $\begin{array}{l}\text { QS. Al- } \\
\text { Baqarah [2] : } \\
258\end{array}$ & $\begin{array}{l}\text { Menang } \\
\text { melawan } \\
\text { kelaliman }\end{array}$ & Pemenang \\
\hline 27 & $\begin{array}{l}\text { QS. QS. Al- } \\
\text { Taubah [9]: } 40\end{array}$ & $\begin{array}{l}\text { Mendapatkan } \\
\text { penjagaan dan } \\
\text { pertolongan } \\
\text { Allah }\end{array}$ & Pemenang \\
\hline 28 & $\begin{array}{l}\text { QS. Al- } \\
\text { Anfāl[8]:15 }\end{array}$ & Tidak pengecut & $\begin{array}{l}\text { Tidak } \\
\text { pengecut }\end{array}$ \\
\hline 29 & $\begin{array}{l}\text { QS. } \\
\text { 'Ali'Imrān[3]: } \\
139\end{array}$ & $\begin{array}{l}\text { Tidak lemah } \\
\text { dan bersedih }\end{array}$ & Tangguh \\
\hline 30 & $\begin{array}{l}\text { QS. Al- } \\
\text { Aḥāb[33]:10 }\end{array}$ & $\begin{array}{l}\text { Yakin akan janji } \\
\text { Allah }\end{array}$ & $\begin{array}{l}\text { Ilahiyah } \\
\text { (terkoneksi } \\
\text { dengan } \\
\text { Allah) }\end{array}$ \\
\hline 31 & $\begin{array}{l}\text { QS. Al- } \\
\text { Ahyāb[33]:22 }\end{array}$ & $\begin{array}{l}\text { Percaya dan } \\
\text { yakin akan janji } \\
\text { Allah }\end{array}$ & $\begin{array}{l}\text { Ilahiyah } \\
\text { (terkoneksi } \\
\text { dengan } \\
\text { Allah) }\end{array}$ \\
\hline
\end{tabular}

Jadi, nilai-nilai yang terdapat dalam ayatayat $\bar{U} l \bar{u}$ 'Azmi dalam Alquran adalah: (1). Bersyukur, (2). Dzi hijr (memiliki daya juang) , (3). Terbuka, (4). rendah hati, (5). Pembelajar, (6). Gigih, (7). Semangat, (8). Pantang menyerah, (9). Tawakal, (10). Ilahiyah (terkoneksi dengan Allah), (11). Pemenang, (12). Pengendalian diri, (13). Patuh, (14). Tunduk, (15). khusyu, (16). Keyakinan, (17). Lembut hati, (18). sopan, (19). Keteguhan, (20). keistiqamahan, (21). Teladan, (22). Tidak pengecut dan (23). Tangguh.

\section{SIMPULAN}

Nilai merupakan sifat yang melekat pada diri seseorang berdasarkan keyakinan ataupun kebiasan yang ditempuh oleh mansuia untuk menghasilkan keyakinan hidup. Maka jika ditinjau nilai-nilai yang dimiliki oleh RasulRasul yang diberi gelar Ulū 'Azmi tidak sebatas sabar, yang dipahami masyarakat luas, namun mempunyai nilai yang lebih luas yaitu nilai-nilai yang dimiliki (1). Bersyukur, (2). Dzi hijr (memiliki daya juang), (3). Terbuka, (4). rendah hati, (5). Pembelajar, (6). Gigih, (7). Semangat, (8). Pantang menyerah, (9). Tawakal, (10). Ilahiyah (terkoneksi dengan Allah), (11). Pemenang, 
(12). Pengendalian diri, (13). Patuh, (14). Tunduk, (15). khusyu, (16). Keyakinan, (17). Lembut hati, (18). sopan, (19). Keteguhan, (20). keistiqamahan, (21). Teladan, (22). Tidak pengecut dan (23). Tangguh.

\section{DAFTAR PUSTAKA}

Al-Dzahabī, Muhammad Husain. Al-tafsīir wa al-Mufassirūn. juz. 1.Äl-Qohiroh: Dār AlHadith, 2005 M.

Al- Qattan, Manna' Khalil. Studi Ilmu-ilmu al-Quran. judul asli: Mabāhith fì 'Ülum al-Qurān, penj. Mudzakir, cet. Ke13.Bogor: Pustaka Litera AntarNusa, 2009), Abdullah, Mawardi, Ūiumul Qur'an (Yogyakarta: Pustaka Pelajar, 2011.

Al-Habsyi, Abu Kautsar dan Ali Yahya. Membangun Generasi Qurani (Pandangan Imam Khomeini dan Syahid Muthahhari), cet. 1. Jakarta: Citra, 2012.

Al-Khālid, Solah Abdul Fatah, Ta'rïf Al-Dāris Bimanāhij al-Mufasirin, Cet. V (Damaskus: Dār Al-Qolam, 1433 H.

Al-Ṣabuni, Muhammad 'Ali , Al-Tíbyān fí Ūūm al-Qur'ān, judul terjemah : Ikhtisar Ulumul Qur'an Praktis, penj. Muhammad Qodirun Nur, Cet. 1.Jakarta: Pustaka Amani, 2001.
Al-Zuhaili, Muhammad, Ibn Kathïr : AlHafidz Al-Mufassir.

Daryanto, Kamus Lengkap Bahasa Indonesia.Surabaya: Apollo, 1998.

Engkoswara, Administrasi Pendidikan Jakarta:tp, 2010.

Lubis, Mawardi. Evaluasi Pendidikan Nilai, Perkembangan Moral Keagamaan Mahasiswa PTAIN .Yogyakarta: Al-Ruzz Media, 2009.

Majid, Abdul dan Dian Andayani. Pendidikan Karakter Perspektif Islam. Cet.2. Bandung:Remaja Rosdakarya, 2012.

Manzūur, Ibn, Lisān al-'Arāb, Cet. 1, jilid 15.Beirut: Dār al-Sadr, 1990.

Mujib, Muhaimin \& Abdul, Pemikiran Pendidikan Islam. Bandung: Trigenda Karya, 1998.

Ramayulis. Ilmu Pendidikan Islam. Cet.9. Jakarta: Kalam Mulia Group, 2012.

Shihab, Quraish. Membumikan Al-Quran "Fungsi dan Peran Wahyu dalam Kehidupan Masyarakat”. Bandung, Mizan Pustaka, 2013.

Zubaedi, "Desain Pendidikan Karakter", Cet.2. Jakarta: Kencana Prenada Media Group, 2012. 